Portland State University

PDXScholar

TREC Final Reports

Transportation Research and Education Center

(TREC)

7-2011

\title{
Transportation Planning Through Mobile Mapping Technology
}

Marc Schlossberg

University of Oregon

Nico Larco

University of Oregon

Ken Kato

University of Oregon

Dana Maher

University of Oregon

Cody Evers

University of Oregon

See next page for additional authors

Follow this and additional works at: https://pdxscholar.library.pdx.edu/trec_reports

Part of the Transportation Commons, and the Urban Studies Commons

Let us know how access to this document benefits you.

\section{Recommended Citation}

Schlossberg, Marc, Nico Larco, Ken Lato, Dana Maher, Cody Evers and Christo Brehm. Transportation Planning Through Mobile Mapping Technology. OTREC-TT-11-01. Portland, OR: Transportation Research and Education Center (TREC), 2011. https://doi.org/10.15760/trec.3

This Report is brought to you for free and open access. It has been accepted for inclusion in TREC Final Reports by an authorized administrator of PDXScholar. Please contact us if we can make this document more accessible: pdxscholar@pdx.edu. 
Authors

Marc Schlossberg, Nico Larco, Ken Kato, Dana Maher, Cody Evers, and Christo Brehm 


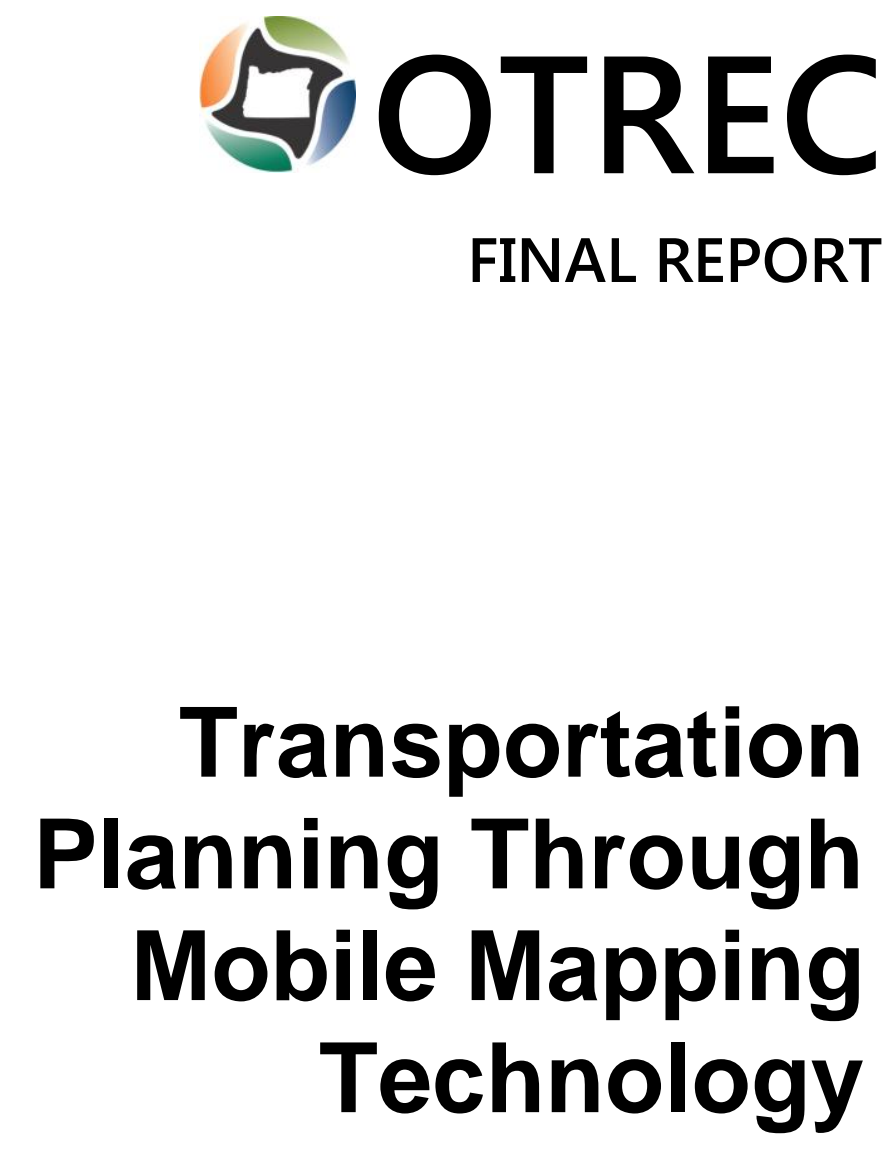

OTREC-TT-11-01

July 2011 



\title{
TRANSPORTATION PLANNING THROUGH MOBILE MAPPING
}

\section{Final Report}

\section{OTREC-TT-11-01}

\author{
by \\ Marc Schlossberg \\ Ken Kato \\ Dana Maher \\ Cody Evers \\ Christo Brehm \\ University of Oregon
}

for

Oregon Transportation Research and Education Consortium (OTREC)

P.O. Box 751

Portland, OR 97207

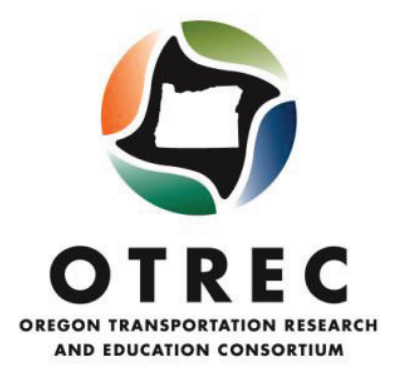

July 2011 



\section{Technical Report Documentation Page}

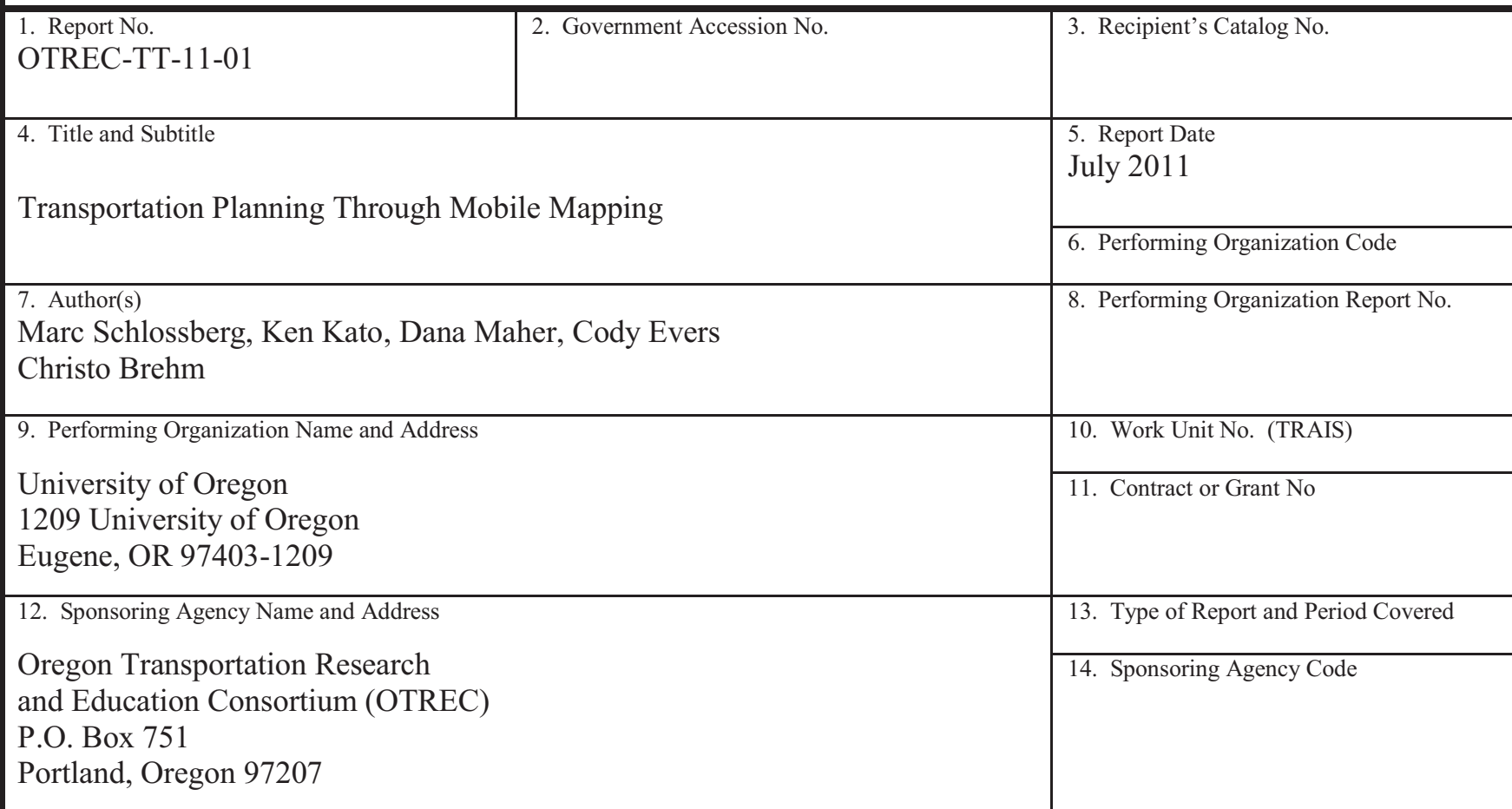

15. Supplementary Notes

\section{Abstract}

This report describes the development and testing of the Fix This Tool, a spatial, participatory, active transportation and built environment assessment tool created on an iPhone platform. The goal of this tool development was to create an instrument that could be widely distributed to communities across the country to develop a spatially based assessment of the micro-scaled elements of their local active transportation environment such that public officials and community members could focus energy in making appropriate improvements.

The development of this tool emerged out of previous work with such tools built on a GIS platform and a workshop-based format to engage residents in data collection of their walking and biking environments. While this past work proved successful in both data collection tool use and in facilitating community conversations, the technological infrastructure had significant limitations in terms of being able to widely distribute the effort. In a GIS-based approach, GIS technicians must be present and when combined with community training and data processing, the cost of development, collection, and distribution is a significant limit to which communities could adopt such assessment tools for their own use.

The Fix This Tool is designed to overcome these distribution and cost barriers by developing a tool that can be easily downloaded by community members using technology they already own. The report that follows outlines the philosophical positioning of a community-based data collection process, describes the tool itself, and provides some reflections between this smart phone based model and the previous GIS-based model of community-engaged active transportation assessment tools.

17. Key Words

18. Distribution Statement

active transportation, built environment, performance metrics, audit tools, GIS, smart phone, pedestrian, bicycle, public participation

No restrictions. Copies available from OTREC: www.otrec.us

\begin{tabular}{l|l|l|l}
\hline 19. Security Classification (of this report) & 20. Security Classification (of this page) & 21. No. of Pages & 22. Price \\
Unclassified & Unclassified & 46 &
\end{tabular}




\section{ACKNOWLEDGEMENTS}

We would like to thank the Oregon Transportation Research and Education Consortium $(O T R E C)$ for their ongoing support of this work, and their interest in finding new ways to engage ordinary residents in the process of improving the nation's active transportation environment.

\section{DISCLAIMER}

The contents of this report reflect the views of the authors, who are solely responsible for the facts and the accuracy of the material and information presented herein. This document is disseminated under the sponsorship of the U.S. Department of Transportation University Transportation Centers Program in the interest of information exchange. The U.S. Government assumes no liability for the contents or use thereof. The contents do not necessarily reflect the official views of the U.S. Government. This report does not constitute a standard, specification, or regulation. 


\section{TABLE OF CONTENTS}

EXECUTIVE SUMMARY AND REPORT CONTENTS ................................................... 1

1.0 INTRODUCTION....................................................................................................... 3

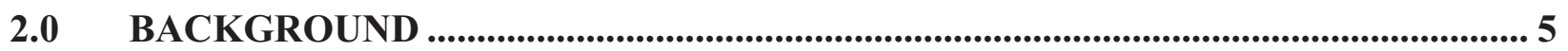

2.1 PUBLIC PARTICIPATION WITHIN GIS .......................................................... 5

2.2 DECENTRALIZED GIS DATA COLLECTION ........................................................ 5

2.3 ENGAGING THE PUBLIC TO COLLECT DATA ............................................... 6

3.0 DESCRIPTION OF THE FIX-THIS TOOL ............................................................... 9

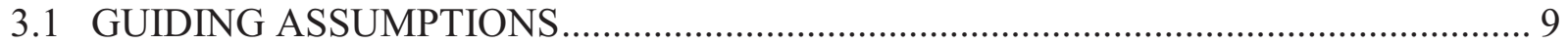

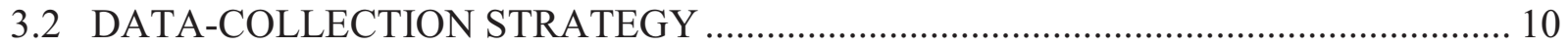

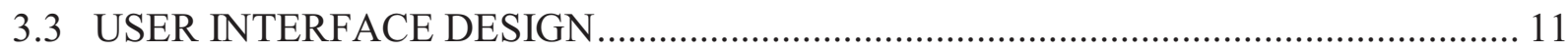

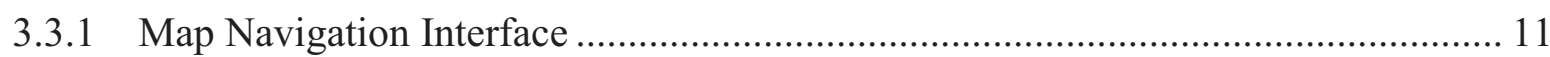

3.3.2 Audit Survey Interface .............................................................................. 14

3.4 DATA MANAGEMENT AND NETWORK COMMUNICATION ........................... 16

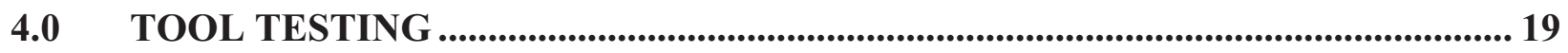

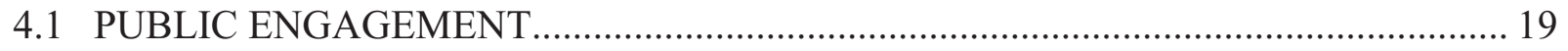

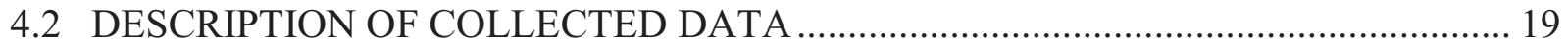

4.3 WHAT WAS WORTH OBSERVING? .................................................................... 20

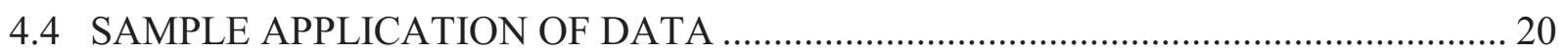



5.1 COMPARISON TO MOBILE-GIS MODEL ....................................................... 23

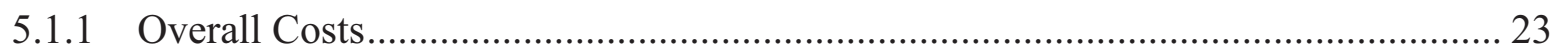

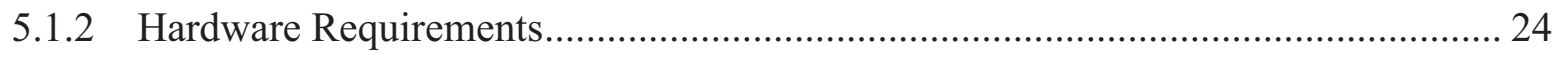

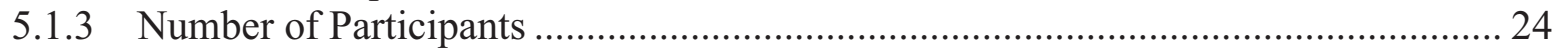

5.1.4 Community Engagement ........................................................................... 24

5.1.5 Programming Requirements ......................................................................... 25

5.1.6 Base Data Requirements ......................................................................... 25



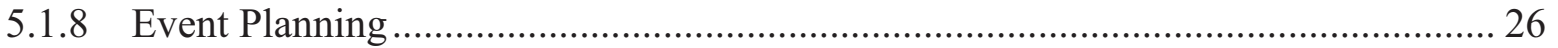

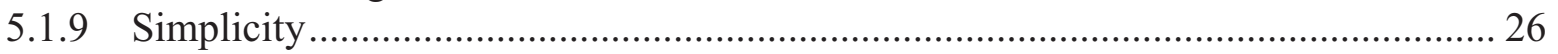

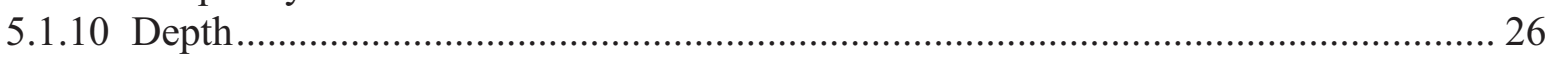





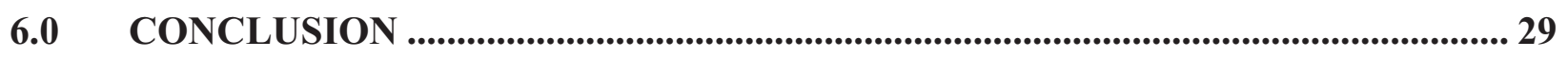

7.0 REFERENCES ...................................................................................................... 31

APPENDIX A: PARTICIPANT INVITATION ....................................... 33

APPENDIX B: PARTICIPANT CONSENT FORM ................................... 35

APPENDIX C: POST-ASSESSMENT SURVEY ....................................... 37 


\section{LIST OF TABLES}

Table 1: Participants use common iPhone navigation and data manipulation gestures. ............. 12

Table 2: Observations on the map screen are colored based on their affective qualities ............ 13

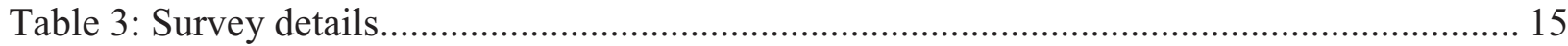

Table 4: Pros and cons of handheld assessment tool platforms ........................................... 23

\section{LIST OF FIGURES}

Figure 1: Distributed approach to data collection and synthesis ......................................... 10

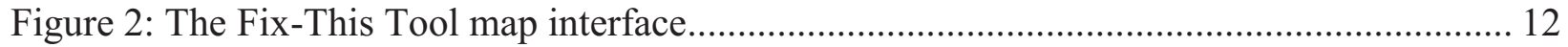

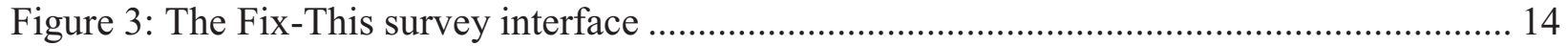

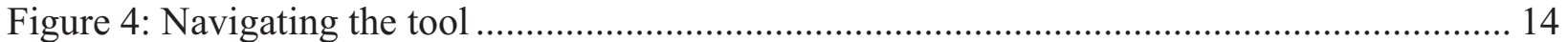

Figure 5: Using integrated data for bicycle boulevard planning ........................................ 22 


\section{EXECUTIVE SUMMARY AND REPORT CONTENTS}

This report describes the development and testing of the Fix-This Tool, a spatial, participatory, active-transportation and built-environment assessment tool created on an iPhone platform. The goal of this tool development was to enhance public participation using new technology by creating an instrument that could be widely distributed to communities across the country to develop a spatially explicit assessment of the micro-scaled elements of local activetransportation environments. This would support local officials and community members in their efforts to prioritize pedestrian/bike improvement projects and interventions.

The development of the Fix-This Tool was based on earlier OTREC-supported work, which utilized a more distributed and intensive participatory process utilizing ArcPad mobile-GIS technology implemented in a public workshop format. While this past work proved successful in both data-collection tool use and in facilitating community conversations, the technological infrastructure had significant limitations that constrained wide distribution of the tool. The previous mobile-GIS approach required significant involvement from GIS technicians, time investments to train users, data processing, and research and development costs. The costs associated with an ArcPad mobile-GIS tool made adoption of the tool impossible for many potential user groups. The Fix-This Tool overcomes many of these distribution and cost barriers by providing a tool that can be directly downloaded by residents using technology they already own. The report that follows outlines the philosophical positioning of a community-based, datacollection process, describes the tool itself, and provides some reflections between this smart phone-based model and the previous mobile-GIS model of community-engaged, activetransportation assessment tools. 


\subsection{INTRODUCTION}

The planning of transportation systems for bicyclists and pedestrians is in its infancy in the United States, overshadowed by the automobile-dominated transportation planning of the last 70 years. Many state and local governments are seeking to remedy this imbalance by shifting to more integrated transportation planning. The meaning of integrated transportation varies by state and community, but overall goals include reduced carbon emissions, reduced congestion, reduced public expenditures, more physical activity and more integrated growth-planning controls.

Federal transportation policy may help motivate the national move to integrate local change. The U.S. Department of Transportation strategic plan lists "livable communities" as a top national goal. From the federal perspective, a livable community supports travel by the most appropriate mode, but one whose success is locally defined. "Complete streets" is one concept envisioning this transformation, arguing that streets should be accessible to multiple modes of transportation, that streets represent destinations as well as corridors for movement, and that this country has largely built "incomplete" streets in this regard over the last 70 years.

Many localities across the country have adopted some form of complete-street policies, but the implementations of such policies remain unclear. Yet local action is not only a function of policy, it is also linked to the availability of data on which to make informed and effective decisions. Current transportation data is often limited, usually consisting of a comprehensive street network, augmented occasionally by lane and speed data. Pedestrian network data are inconsistent and rarely complete, even when adjacent to the streets. Pedestrian walk-volume data is nonexistent. Bicycle data is equally limited, including mostly nonexistent understanding of what constitutes appropriate bicycle infrastructure for a range of potential users. These deficiencies are somewhat self-perpetuating; while walking and bicycling ride share remain low, local governments have little demand to rectify existing data gaps, which then prevents decisions from being made on appropriate data.

The challenge thus becomes: (a) filling this gap in a cost-effective way that addresses the local scale important to pedestrian and cycling networks while scaling to larger contexts and (b) defining the data types necessary to evaluate the built environment's capacity to support nonautomotive forms of transportation.

An additional goal and challenge in this area of work revolves around engaging the public in a meaningful way in transportation decision making at the local level. New technology may facilitate a general public to become both creators and users of data, as well as active participants in local change processes. Past OTREC-supported work work on participatory active transportation audit instruments have relied on native GIS tools that required significant technical expertise to manage, even if the interface for the end user was somewhat straightforward. Distribution of tools were limited to individual PDAs (Personal Digital Assistants) and generally facilitated through a community workshop environment. While the 
advantage of this past model includes the ability to facilitate on-site community discussions alongside data collection in the field, the technology simply did not allow for wider distribution, and thus greater participation and data creating throughout a community.

This challenge became the motivation for this project: To adapt active-transportation, field- and GIS-based, public-participatory, data-gathering tools to new forms of mobile and location-aware technology that increasingly is in the hands of the lay public. The broad goal is development of a mobile data-collection tool easily and freely accessible to the public, requiring little to no training, and capable of linking resident input to geographic points of interest. This tool will build local and national bicycle and walking datasets useful to researchers and communities."

Key questions that motivated the development of this tool include:

- What is the character of engagement within this new model and how does it relate to both the hard and soft benefits that may result from these processes?

- What is the nature of the data collection? What is it effective at describing, and where do gaps remain?

- Is there any indication that a distributed model is more cost-effective at addressing existing logistic barriers?

The remainder of this report describes the development and testing of the Fix-This Tool, an iPhone-based tool that allows users to record spatially explicit data about the quality of their local pedestrian or bicycling environment. 


\subsection{BACKGROUND}

\subsection{PUBLIC PARTICIPATION WITHIN GIS}

Using GIS for local government decision making is not a new concept (O'Looney, 2000), and perhaps surprisingly to some, neither is connecting ordinary residents to GIS for local community decision making. Because people who are walking or bicycling are more attuned to the characteristics of the street environment than people driving in cars, it is appropriate that their experiences and perception of the environment should play a key role in both transportation planning and the transition toward enhanced livability. Documenting these experiences produces data useful for improving local conditions, and the participation process itself may lead to social learning (Bull, Petts and Evans, 2008). Research suggests that the participation process may be just as important as the data that are collected; as people re-imagine their local environment in terms of biking or walking, they may consider or envision increasing use of those modes.

Various uses of participatory GIS have leveraged fairly sophisticated GIS technology for lay people (Harris, 1998; Obermeyer, 1998; Talen, 2000; English and Feaster, 2003; Arnstein, 1969), including preliminary experimentation engaging citizens with active transportation (Schlossberg and Brehm, 2009). These include both "soft" benefits, such as the development of social and political capital, and "hard" benefits, such as data collection and project prioritization. Community members surveying their own transportation environment free up agency resources and direct agency attention to areas in need. Further, cultivating an engaged and empowered citizenry can have long-term benefits such as the establishment of trust (Arnstein, 1969) and the creation of momentum towards meeting national livability goals through city redesign.

\subsection{DECENTRALIZED GIS DATA COLLECTION}

GIS capacity tends to be limited and centrally concentrated. While many cities have some GIS capacity internally, most GIS units are limited in scale and appropriately focus their efforts on broad representations of spatial phenomena. Furthermore, transportation departments tend to focus GIS resources on automobile-based transportation, making it difficult to direct existing city GIS resources towards other forms of transportation.

Engagement of the public in active-transportation GIS data collection benefits both planning agencies and communities. However, the use of existing GIS data-collection tools in this manner requires the involvement of significant technical expertise. This reliance on technical staff to facilitate GIS data collection contributes to the expense and limits the geographic and social coverage of the collected data. Overcoming these barriers within a traditional GIS environment is difficult.

Decentralized data collection can overcome the limitations of traditional GIS. In this process: (a) spatial data is collected outside of a centralized GIS system; (b) data-entry devices are privately owned and widely distributed, and (c) data is collected and analyzed without a trained GIS technician. In this alternative scenario, the general public collects data on their own time, based 
on their own interests or concerns. For instance, a cyclist riding to work may wish to note the presence of a sewer grate within the likely line of travel. She can collect data on this deficiency to make it known to the proper authorities as well as other bike commuters. This approach allows for a more comprehensive survey of transportation infrastructure, particularly specific barriers to walking and biking.

\subsection{ENGAGING THE PUBLIC TO COLLECT DATA}

The use of public participation within transportation planning and research is varied. Most often, public participation is enlisted as a means of providing public opinion and creating public buy-in. Less frequently, public participation may be used to guide the goals and design of the project. Schlossberg (2003) argues that the conceptions of "public" and "participation" central to public participation should be approached more critically.

Engaging the public could be a useful approach to community-wide data collection, increasing both the number of eyes in the field and the types of data observed. However, publicly collected data is often criticized for lack of rigor and objectivity. For the average transportation user, "objective" data based on instrument counts may seem abstract or trivial. "Although analysis is certainly important in some decision-making circumstances, reliance on affect and emotion is a quicker, easier, and more efficient way to navigate in a complex, uncertain, and sometimes dangerous world" (Slovic, 2007).

Affect refers to "the specific quality of goodness or badness (a) experienced as a feeling state (with or without consciousness) and (b) demarcating a positive or negative quality of a stimulus" (Slovic, 2007). For example, a mother driving her child to school on a daily basis is not aware of what specific factors might make letting her child walk to school unsafe, but still drives out of a feeling of concern. This is a decision based on intuition born out of socialization and context. Similarly, the routine decision to cross a street at a given point uses information from the moment, despite such information being largely intuitive and incomplete. This is a decision based on instant and incomplete data. Research has shown that these two forms of decision making interact (Slovic et al., 2004). If a person believes something is "good," they are more likely to perceive higher benefit in the action and a lower degree of risk, irrespective of any logical conclusion to the contrary. Likewise, a bad decision accentuates possible risks and attenuates perceived benefits.

Therefore, the benefits of any safety interventions are moot if the individual continues to perceive the environment as hostile or dangerous (i.e., affectively bad). For example, while many cities now provide dedicated bike lanes on arterial roadways, only the least risk-adverse individuals actually use those facilities.

Pedestrians and cyclists perceive the built environment at a higher resolution than motorists, noticing a great deal of local context that is difficult to document centrally. Engagement of active-transportation users in decentralized, participatory GIS can create a new data-aggregation scheme capable of documenting these important local details and facilitating pedestrian and biking infrastructure development. Incorporating intuition and affect into the process may be a challenge to current transportation professionals, but is necessary to fully understand how the built environment supports or dissuades walking and biking trips. The Fix-This Tool is an effort 
to bridge divides between active-transportation users, larger communities, and transportation planning and research groups. 


\subsection{DESCRIPTION OF THE FIX-THIS TOOL}

The Fix-This Tool is a proof-of-concept mobile survey tool capable of quick, easy and free distribution to anyone in the country. Our primary motivation was the creation of a distribution system that didn't require specialized hardware and extended setup. Project overhead consisted of several Macintosh computers for software development, an IBM server to handle live data storage and recall, a single copy of ArcGIS for GIS data analysis and visualization, and a suite of iPhones for testing and data collection. After developing a similar tool or extending this one, a city could either replicate our model of device purchase and controlled distribution or simply take advantage of iPhones (or other smart phones) already in public hands.

\subsection{GUIDING ASSUMPTIONS}

The surveys developed using the Fix-This Tool revolved around the assumptions that a) people are sensitive to their environment; that $b$ ) transportation decisions are made intuitively based on momentary and incomplete information; and that c) data should be assembled to prioritize qualitative insights and reactions over more narrowly defined objective indicators

The Fix-This Tool was itself designed around four assumptions of how pedestrians and bicyclists experience the surrounding built environment:

1. Environmental Sensitivity: Walkers, bikers and public transit users are more sensitive to fine-grain details of their surroundings than someone who is in a car. Some areas of any city are more pleasant to walk and bike than others. Areas of the city perceived as equally pleasant or safe by motorists may be viewed as highly disparate by cyclists and pedestrians. The basis for the Fix-This Tool is to allow people to take note of the things that affect them while walking and biking in those areas of the city where they travel.

2. Risk Aversion: People choose routes and modes of transportation that minimize risk. Risk perception depends on many factors, including an individual's existing conceptions of walking and biking. Perception of benefits and risks is highly individual. Data collected using the Fix-This Tool is user-defined and allows for "redundant" observations between multiple persons traveling in the same area. The data submitted by a person may be very detailed and specific to a situation or may be very general.

3. Observations are Affective by Nature: People intuitively and instantly understand the built environment in terms of good or bad. How these factors add up to the feelings of comfort and safety may not make rational sense. The Fix-This Tool asks follow-up questions based around this affective quality of the observation (e.g., good/bad).

4. Ambiguity of Affective Data: A person can identify places where they feel uncomfortable or unsafe even though they may be unable to identify or convey every contributing factor. Further, individual decisions are never based on a complete inventory of the surroundings. The Fix-This Tool is designed to handle all observations, whether 
they refer to something built (e.g., streets, signage, etc.) or something felt (e.g., danger, poor lighting, etc.).

\subsection{DATA-COLLECTION STRATEGY}

Our use of smart phones as data-collection devices differs markedly from other public engagement tools - including those that our lab had developed in the past - because there is no technical limit to the number of devices that can be simultaneously "enlisted" in the datacollection process (Figure 1). We describe the data-collection process as "decentralized" because: (a) the survey devices are not "centrally owned" - they are privately owned smart phones; and (b) the data-collection process does not require any preparation or oversight by a GIS professional.

Figure 1: Distributed approach to data collection and synthesis



Using privately owned smart phones, participants install the Fix-This Tool, record a distinct set of observations, and then synchronize this data automatically with a central server where it is available for download and analysis. The Fix-This Tool sends data to the central server automatically and in real time. This process makes the recording of observations easier for the user while providing additional information about how, where and when data is collected by public participants. For instance, in addition to the actual survey data (discussed below), the iPhones automatically transmit metadata such as the exact time the record was made. 
In order to test the validity of the decentralized concept, we first elected to utilize a hybrid centralized/decentralized approach. We purchased 10 iPhones with pre-paid data plans and lent them for a week through a self-selecting group of university student volunteers. The Fix-This Tool was preloaded on each iPhone. Each user entered a unique identifier into the Fix-This Tool installation on their phone, allowing us to separate data by participant and limiting the data displayed to only those made by the current user. Testers were instructed to note "those things they felt important to note and share on those routes that they regularly bike and walk within any given week." When each participant returned the iPhone, they were given a short, five-minute survey concerning their transportation decisions, perceptions on the data-collection process, and application ease of use. In a fully decentralized model, such interaction and feedback mechanisms would be embedded in the software or otherwise automated.

It is worth noting that while the Fix-This Tool is currently iPhone specific, the development approach could be easily adapted to other smart phones. We selected the iPhone as our development platform because lay technology users seemed remarkably comfortable using their finger to navigate maps and applications. We noted that this system is much more intuitive than previous mobile-GIS systems that required using a cursor pad and/or pen touchscreen, and at the time of the tool development the iPhone provided the most robust touchscreen in the market. Moreover, this touchscreen technology appears to be quickly becoming an industry standard, and similar interfaces are already found on smart phones using competing operating systems (notably Android).

\subsection{USER INTERFACE DESIGN}

The Fix-This App is made up of two principle interfaces; the map interface and the survey interface. The user of the application is continually switching between the navigation of the local built environment and entering information about their street-level observations.

\subsubsection{Map Navigation Interface}

Participants note their observations of the built environment using a map interface created using the Google Maps Application Programming Interface (API). An API is a set of tools for bringing functionality, such as the map display and interaction features of Google maps, to a custom application. The map interface allows the user to selflocate, explore the surrounding area, and zoom in and out (

Figure 2). Navigation is aided by the iPhone's built-in GPS unit, which automatically orients a global map to the location of the user. When the GPS unit is turned on, the screen extent is locked to the participant's current GPS location and will follow the user. When turned off, the user can scroll freely to other locations in the city, which may be useful in order to record previously noted observations not yet entered. 


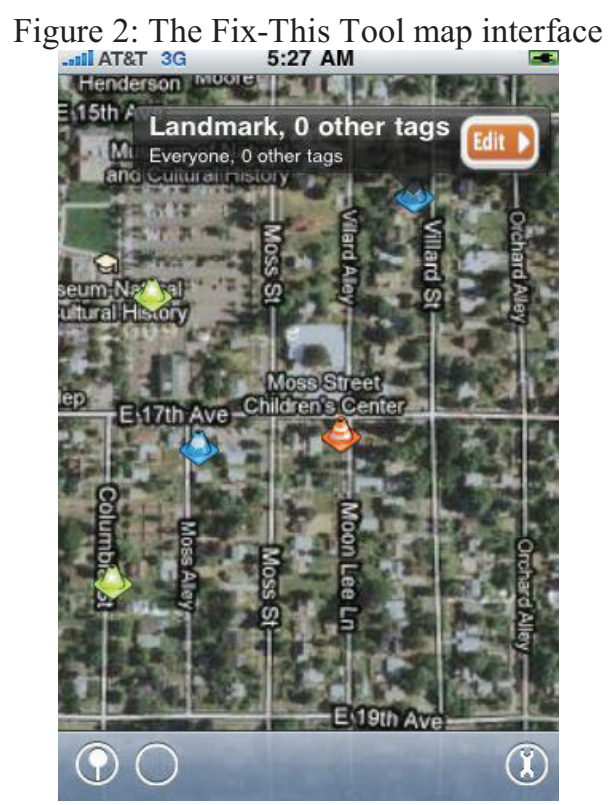

The mapping interface is controlled using simple "finger gestures," made popular and possible by the touchscreen interface of the iPhone (Table 1). Participants found the iPhone's physical design and user interface to be highly intuitive. Often, participants required little or no explanation before they were able to locate familiar locations within their neighborhood, scroll to their current location, and shift the map extent in and out to best visualize the surrounding area. The ease of use is especially worth noting when compared to the mobile-PDA devices used in previous work.

Table 1: Participants use common iPhone navigation and data manipulation gestures.



Single Tap: Default means for navigating the toolbars and audit tables. When a single tap is registered over an existing observation, a window is opened that gives basic information on the observation and allows the user to add or edit additional information.

Finger Swipe: Swiping the index finger across the screen moves the


map. This system replicates the experience of a person looking down at a table with a map through a lighted magnifying glass. Rather than moving their eyes to view a different part of the map, the person physically moves the map to align with the lens point of view. 


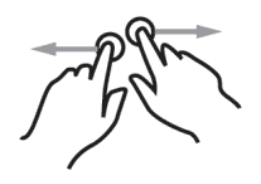

Two-Finger Pinch: By placing the index finger and thumb on the screen, and pulling the two fingers together, the map zooms in to the extent of the "pinch." Zooming out is similarly accomplished by placing the index and thumb together and then spreading out (i.e., pinching out).

Tap and Drag: As noted, a single tap registered above an

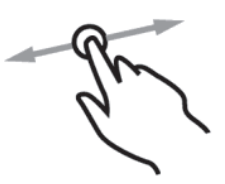
observation already existing on the map opens a window displaying details. By tapping and maintaining the index finger pressed over the observation for two seconds, the user can then drag the observation to a new location on the map, or fine tune its placement.

Double Tap: A new observation is registered by either double tapping the desired location on the map, or allowing the device to automatically point at the current GPS location. Either way, the latitude and longitude of the selected location is appended to the form.

Observations are displayed on the map screen as small traffic cones (Table 2). Each traffic cone represents a single observation made by the participant. The color of the traffic cone displays the affected quality (e.g., good/bad) noted for the observation, making it is easy for participants to distinguish between assets (good things) and obstacles (bad things). Overlapping icons can be distinguished from each other by zooming in further.

Table 2: Observations on the map screen are colored based on their affective qualities

Obstacles (red): Observations described as negative are colored red. Observations described as "very bad" are a more saturated red.



Assets (green): Observations described as positive are colored green. Observations described as "very good" are a more saturated green.

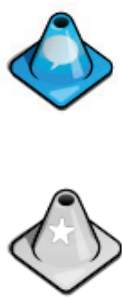

Noteworthy (blue): Some important observations are value neutral. Observations that are "just worth noting" are colored blue.

Inactive (grey): In order to protect the integrity of the data while it is being synced with the remote server, observations that have been recently noted or recently edited are made inactive and displayed as gray.

In the data-entry mode, the application is used as an audit tool rather than for navigation or looking up information, which means that observations displayed are limited to only those collected by each participant. In data-browsing mode, observations from a single user or all users is accessible to help create optimized route planning. 


\subsubsection{Audit Survey Interface}

Packets of user input are wrapped in discrete observations linked to specific geographic locations that are symbolized on the map with the icons from Table 2. The map thus catalogues all observations previously made by the user. Previous observations can be viewed and edited within the survey interface (Figure 3).

Figure 3: The Fix-This survey interface

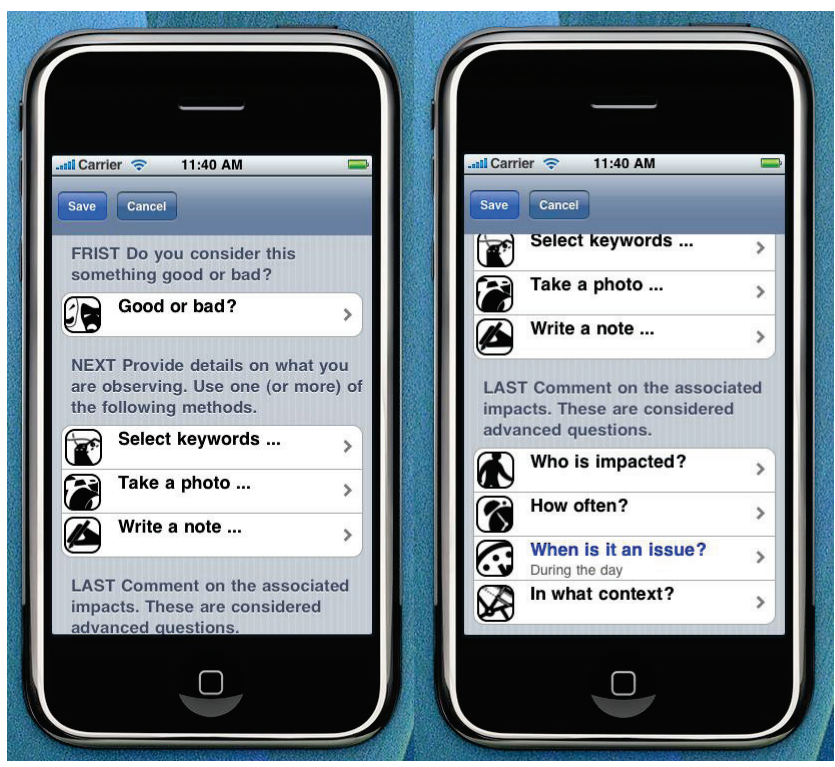

The survey consists of a series of questions organized in three sections, each of which is answered from a central survey screen. A table of possible responses accompanies most questions, although several free-response options are available, including the ability to attach an image to the survey form.

Figure 4: Navigating the tool
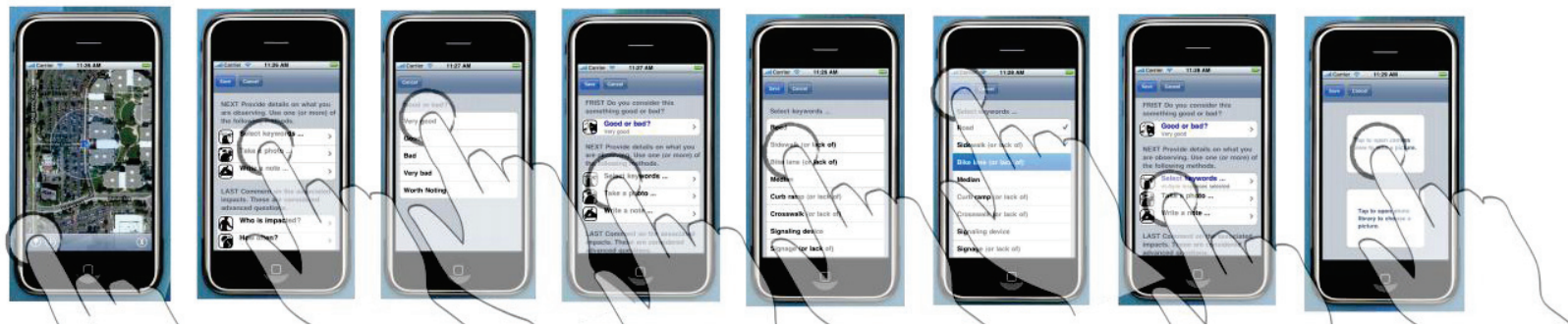

The user can answer the questions in any order and some responses are optional. Mandatory questions are noted as such and users are unable to save their observations until these questions are answered. All of the wording and question responses are taken from a separate table saved on the iPhone, allowing the content of the form to be updated without additional programming. 
Table 3 enumerates the current survey questions, their potential responses, whether they are required, and whether more than one answer per question is permissible.

Table 3: Survey details

\begin{tabular}{|c|c|c|c|c|c|}
\hline Section & Icon & Question & Responses & & $\frac{0}{\frac{0}{2}} \cdot \frac{0}{2}$ \\
\hline 总 & & $\begin{array}{l}\text { Affect: } \\
\text { Do you consider this } \\
\text { something good or bad? }\end{array}$ & $\begin{array}{l}\text { Very good } \boldsymbol{x} \text { Good } \boldsymbol{x} \\
\text { Neutral } \boldsymbol{x} \text { Bad } \boldsymbol{x} \text { Very bad }\end{array}$ & $\mathrm{N}$ & $\mathrm{N}$ \\
\hline \multirow{3}{*}{ 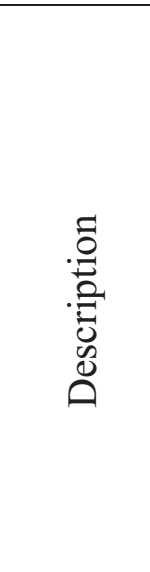 } & & $\begin{array}{l}\text { Keyword: } \\
\text { Select keywords that } \\
\text { describe the } \\
\text { observation... }\end{array}$ & $\begin{array}{l}\text { Road } \boldsymbol{*} \text { Sidewalk } \boldsymbol{*} \text { Bike } \\
\text { Lane } \boldsymbol{*} \text { Median } \boldsymbol{*} \text { Curb } \\
\text { Ramp } \boldsymbol{*} \text { Crosswalk } \boldsymbol{*} \text {.. } \\
\boldsymbol{*} \text { Other }\end{array}$ & $\mathrm{N}$ & $\mathrm{Y}$ \\
\hline & & $\begin{array}{l}\text { Photo: } \\
\text { Take a photo... }\end{array}$ & $\begin{array}{l}\text { Take a Picture } \boldsymbol{*} \text { Choose a } \\
\text { Picture from Library }\end{array}$ & $\mathrm{Y}$ & $\mathrm{n} / \mathrm{a}$ \\
\hline & & $\begin{array}{l}\text { Text: Describe the } \\
\text { observation with text... }\end{array}$ & $\begin{array}{l}\text { Enter text w/ touch } \\
\text { keyboard }\end{array}$ & $\mathrm{Y}$ & $\mathrm{n} / \mathrm{a}$ \\
\hline \multirow{4}{*}{ 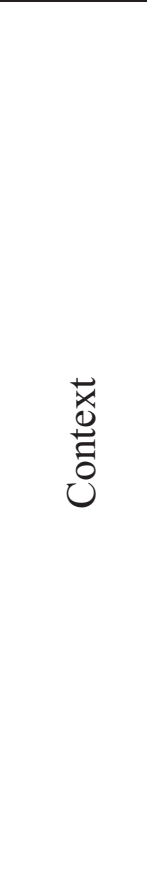 } & & $\begin{array}{l}\text { Users: } \\
\text { Who is impacted? }\end{array}$ & $\begin{array}{l}\text { Bikers } \boldsymbol{x} \text { Walkers } \boldsymbol{x} \\
\text { Motorists } \boldsymbol{x} \text { Disabled } \boldsymbol{x} \\
\text { Children } \boldsymbol{*} \text { Elderly } \boldsymbol{*} \\
\text { Other }\end{array}$ & $\mathrm{N}$ & $\mathrm{Y}$ \\
\hline & & $\begin{array}{l}\text { When: } \\
\text { When is it an issue? }\end{array}$ & $\begin{array}{l}\text { During the day } \boldsymbol{*} \text { When } \\
\text { dark } \boldsymbol{*} \text { Rush hour } \boldsymbol{*} \text { All } \\
\text { the time } \boldsymbol{*} \text { Poor weather } \boldsymbol{x} \\
\text { Not sure }\end{array}$ & $\mathrm{Y}$ & $\mathrm{N}$ \\
\hline & & $\begin{array}{l}\text { Frequency: } \\
\text { How often do you notice } \\
\text { it? }\end{array}$ & $\begin{array}{l}\text { Rarely } \boldsymbol{x} \text { Sometimes } \boldsymbol{x} \\
\text { Often } \boldsymbol{x} \text { Always } \boldsymbol{x} \text { Not } \\
\text { sure }\end{array}$ & $\mathrm{Y}$ & $\mathrm{N}$ \\
\hline & & $\begin{array}{l}\text { Extent: } \\
\text { In what context would } \\
\text { you place the } \\
\text { observation? }\end{array}$ & $\begin{array}{l}\text { Something I can point to } \boldsymbol{x} \\
\text { Relates to a crossing/area } \boldsymbol{x} \\
\text { Relates to a street } \boldsymbol{x} \text { Too } \\
\text { complex/vague to place } \boldsymbol{x} \\
\text { Not Sure }\end{array}$ & $\mathrm{Y}$ & $\mathrm{N}$ \\
\hline
\end{tabular}


Subjective Affect Question: The survey first asks the user to describe the affective quality of the observation. This question is intentionally placed first to capture the affective qualities, or the initial subjective reaction, of the individual before introducing any bias through the assessment of objective aspects of the built environment.

Descriptive Built Environment Questions: The survey then asks the user to describe their observation in one or more ways: categorically, visually or written. Since the street-audit tool was designed to be simple, flexible and quick to use, the Fix-This Tool tries to avoid text entry as a primary form of data collection. This both decreases the time necessary to enter data into the smart phone and later facilitates the interpretation of data.

Context Questions: The third set of questions pertain to the context of the observation, including who the issue will most likely affect, when it is an issue, and the spatial extent of the problem. These questions are designed to help understand the starting place for potential interventions.

\subsection{DATA MANAGEMENT AND NETWORK COMMUNICATION}

The Fix-This Tool manages network commands using a queuing system. Whenever a change is made locally (e.g., making a new observation or editing an existing observation), a command is placed in a network communication queue with the server. The network communication queue is handled in parallel to the application, allowing the user to continue to queue additional commands (e.g., observations and searches) even if the device/server has not yet completed previous commands.

Commands are wirelessly sent to the central data server, allowing data to be maintained between the hand-held smart phone and the server. There are three main types of queries that are sent between an iPhone and the central map server: 1) New Observations 2) Edited Observations, and 3) Searches.

- New Observation: The application tags new observations with a temporary ID constructed from the exact time the observation was made (down to the millisecond). The application compiles the temporary ID and observation data into a single data packet and passes the packet to the server. The server then generates a separate ID for the observation based on the order in which it was received. The server sends a confirmation message back to the remote device, which includes both the temporary ID and the unique server ID. The application searches local observations for the observation that matches the temporary ID found in the confirmation message and assigns the network ID in its place.

- Edit Observation: Users can edit data after the server has recorded it. Edits are accomplished by replacing items on the server that contain the same network ID as the point being edited. The command contains the network ID of the observation and the complete data dictionary of the edited point. The server confirms the edit and the local point is unlocked. 
- Search: The Fix-This Tool can submit a simple SQL query search to the server. The server extracts this query and sends back the relevant data as a continuous string to the mobile device. The application parses the search string into individual observations. The search function was not activated within the version of the application used with study participants.

Once the network action has reached the top of the queue, commands and data are sent as a XML text string over the iPhone's wireless network using HTTP protocol. The server receives this data, parses the XML string, stores it within the online SQL database, and sends a response string back to the mobile device.

Once a network command is successfully executed, it is removed from the local queue and the next command is run. If the data transfer fails, the command remains in the queue and the program attempts to make the transfer periodically until it goes through or a retry threshold is reached. Since the communication queue is run as a parallel process to the main application, users can continue to add and edit other observations.

The observation is locked until confirmation from the server is received (indicated as a gray cone on the map). The user is unable to make any additional changes to that particular observation until the observation icon is re-colored. 


\subsection{TOOL TESTING}

Upon completion of a Fix-This Tool beta, pilot testing commenced on individuals untrained in data-gathering tools and not involved in active-transportation work or advocacy, with the intent of exploring the validity of the decentralized data-collection process. This exploration sought to explain the data-collection process with the following questions in mind:

- What spatial distributions or patterns are seen in decentralized data collection? What environmental factors are commonly noted?

- How, where and when do participants collect data? How do participants understand the data-collection process?

- Is the process intuitive and transparent to users?

Exploring these questions assesses the feasibility of creating and implementing a framework for a decentralized, community-driven system for collecting geospatial data relating to active transportation and the creation of livable communities.

\subsection{PUBLIC ENGAGEMENT}

Our participatory sample consisted of 25 self-selected volunteers. The participants were primarily university students (91\%), male (64\%), and under the age of 25 (64\%). Most volunteers used alternative modes of transportation, reporting on average 12 hours spent weekly either biking or walking. Very few hours on average were reported spent in a car. Each participant was loaned an iPhone with the Fix-This Tool preloaded.

\subsection{DESCRIPTION OF COLLECTED DATA}

Over the four-week data-collection period, 307 data points were recorded over an area of approximately five square miles, with the majority of data focused in or near the University of Oregon campus. On average, volunteers noted 18 points of interest during the weeklong period they had their iPhone, although actual numbers varied largely by individuals. Most observations were made shortly after receiving or shortly before returning the iPhone.

Observations were noted at all points of the day, although presumably reflected those times most likely to be in transit: Two-thirds of observations were made in the morning (33\%) or at mid-day $(33 \%)$.

Volunteers noted that in the majority of instances, observations were recorded on location as opposed to at home, school or work after commuting. Volunteers also explained that observations were noted immediately (as opposed to returning to the location at a later point or entering data elsewhere), and that they would note observations in clustered series, presumably at or near the same location. 


\subsection{WHAT WAS WORTH OBSERVING?}

As described previously, the survey was structured around the affective qualities of the built environment. The majority of observations noted were considered bad ( $41 \%$ bad and $24 \%$ very bad). Interestingly, however, nearly one quarter of the responses noted something felt as good (11\% good and $11 \%$ very good). The remaining observations (13\%) were seen as value neutral.

Participants were asked to describe their observation in one or more ways, categorizing the issue by keyword, photo or as a custom description written by the user. While users were required to categorize the observation, both photos and text were optional. In nearly two-thirds of instances users submitted additional text (63\%), and took photos in $25 \%$ of observations.

In the majority of observations noted, users felt the issue could be categorized as either related to the road ( $25 \%$ of all observations), bike lane $(28 \%)$ or sidewalk $(21 \%)$. In approximately half as many cases, users described issues related to crossings or intersections. And in approximately half as many as those, issues were categorized in terms of signage or the signaling device. Notably, very few noted observations related to routing, hills or curves. Most issues were described in terms of one or two of the categories provided (average number of categories selected $=1.67$ ); in some instances, however, as many as nine keywords were selected.

The survey did not require users to answer all questions, leaving four potentially abstract or inapplicable questions as optional. Two of these four questions, "user groups affected" and "time most notable," received 100\% response rates despite being optional. For the other two, the "frequency of observation" category achieved a $23 \%$ response rate and the "area affected" category achieves a rate of $33 \%$. Notably, user exit interviews identified confusion over how to accurately identify "area affected" using the provided options.

When asked to assess which user groups were most affected by the issue being noted, cyclists and walkers were cited in the majority of instances. In about a third of all instances, disabled persons and motorists were noted. Elderly people and children were the groups least noted to be affected by observed issues. Most issues were described as relevant to more than just a single user group (average number of user groups noted $=2.56$ ). The self-selected set of university students as data assessors may explain the biases of responses. Although this testing only intended to explore the Fix-This Tool's functionality, such response bias does bring up a significantly larger question: For a system like the Fix-This Tool, how can data be collected for people who do not use active transportation but may desire to?

The majority of observations pertained to permanent, constant elements of the transportation or built environment (53\%). Likewise, the vast majority of issues noted were seen as prevalent at all points of the day $(42 \%)$ or only during the day $(53 \%)$.

\subsection{SAMPLE APPLICATION OF DATA}

Because the data is spatially located using the latitude and longitude of the observation, it can be isolated or aggregated with GIS as needed. For example, suppose the City of Eugene wishes to embark on a significant upgrading of its bicycle infrastructure, beginning with the creation of a signature bicycle boulevard along Alder Street. 
Figure 5 illustrates how three different pieces of data can be extracted from the tool to assist in this corridor planning. Individual observations have been aggregated into a spatial density map and color coded by an aggregated average rating of quality, with darker areas to the north representing areas with a poorer rating compared to the lighter areas of the south. This central map thus represents a way to aggregate individual data points into a summarized form that can be used for larger scale analysis.

To the right of the image, the experiences of users along the corridors in the form of individual comments are presented because these individual details are extremely important in creating an environment that works well for pedestrians and cyclists.

This approach in some ways is similar to community forums where residents are asked to place Post-it notes on a map indicating areas of concern. In the digital format of the Fix-This Tool, however, such individual, point-specific observations can be extracted as needed by public or civic organizations. Finally, users can take advantage of the iPhone camera that is directly integrated into the tool to capture images of an issue. The photos on the left can be powerful visual evidence to show officials exactly what it is about specific aspects of the environment that are important or impactful to a variety of users. 
Figure 5: Using integrated data for bicycle boulevard planning

Muge puddle that forces bikes to go around into traffic
Milyard, which intes in roadway create hazard
Ailder bike lane in serios need of repair




\subsection{REFLECTIONS}

\subsection{COMPARISON TO MOBILE-GIS MODEL}

An open question at the beginning of this project related to how this iPhone-based infrastructure may compare to a mobile-GIS-based approach that uses more traditional GIS software at its core, as discussed in OTREC Report OTREC-TT-09-02 (2009). This project developed a decentralized, participatory tool for assessing the built environment using handheld GPS units. While the project was successful, it raises issues of scalability; significant technical and financial commitments are required of communities or agencies desiring to utilize the process. The FixThis Tool is a response to this issue that takes advantage of the growth of smart phone usage and significant increases in smart phone capabilities.

Table 4 compares each type of technology on several different variables, and following sections explore these issues more fully.

Table 4: Pros and cons of handheld assessment tool platforms

\begin{tabular}{|l|c|c|}
\hline Element & iPhone & Mobile GIS \\
\hline Overall cost & + & - \\
\hline Hardware & o & o \\
\hline Number of potential participants & + & - \\
\hline Controlled community engagement & - & + \\
\hline Device software & + & - \\
\hline Programming software & + & o \\
\hline Base data & + & - \\
\hline Usability & + & + \\
\hline Expandability & + & - \\
\hline Event planning & 0 & - \\
\hline Simplicity & + & - \\
\hline Depth & - & + \\
\hline Data management & o & o \\
\hline Data access "+"= positive “-"=negative & "o"= neutral \\
\hline Community building & + & - \\
\hline Community dialog / education & + \\
\hline
\end{tabular}

\subsubsection{Overall Costs}

Past experience has shown that purchasing and distributing mobile-GIS devices and coordinating data collection are primary cost barriers inhibiting much wider adoption of PPGIS technology. The decentralized smart-phone participation model reduces costs by utilizing devices already in public hands, reducing reliance on specialized training and streamlining the data-synchronization process. Below we compare the estimated costs to conduct studies of similar sizes using a centralized GIS-based, workshop-based, participation model (GISM) and a smart-phone, decentralized participation model (SPM). 


\subsubsection{Hardware Requirements}

Data collection is an expensive and time-consuming task. Involving community members can minimize the costs of employing technicians to collect data while involving many educational and empowerment benefits. Nonetheless, the technology required to record the data is often expensive. For instance, the GISM-participation model requires the community to purchase 2030 PDAs (\$300-\$600 each), depending on scale and number of participants, and a single laptop to be used for data dissemination and synchronization. The cost for the community can exceed $\$ 10,000$.

Costs can be minimized by using smart phones already in the hands of the public within the distributed-participation model. While the growth of such phones is rapidly accelerating, in communities where access to smart phones is limited the local government or advocacy organizations may wish to purchase a number of phones $(\$ 200$ each) and data plans $(\$ 1,440$ for two years) to be used during the data-collection period. Since the SPM model doesn't rely on a workshop to coordinate data collection, the community can minimize costs by using the same set of iPhones across multiple sets of participants. As a result, the cost to supply the necessary hardware depends on the demographic group that participates. Community cost: $\$ 0$ - $\$ 10,000$ (for six iPhone and data plans).

\subsubsection{Number of Participants}

Public participation can be complex and costly, even with relatively few participants. Involving the public within technical procedures such as geographic data collection can make data management harder and the whole process more costly. A distributed-participation model may bypass this bottleneck by providing a simpler structure for participation. Furthermore, it may allow for a certain economy of scale. The data management required for involving 100 participants in the distributed model is much less than a similarly sized group of participants within the workshop-based format.

\subsubsection{Community Engagement}

The actual data collection represents only a fraction of the time spent during a typical workshop used in the GISM model. Indeed, as much of half the time spent during the workshop can be spent within the community discussion following data collection in the field. This time provides a number of secondary benefits, including education and community building. Participants tend to return from data collection in the field armed with new awareness, new insights and new vocabulary. Dialogue inevitably follows upon seeing similar observations from fellow participants.

The benefits gained by community dialogue are important and lasting. The coalitions that arise from such group sessions can create a vanguard for local community change, a phenomena at the heart of grassroots movements. In this sense, the process of data collection may actually yield more community benefit than the actual data collected.

In this approach to community empowerment, we are suggesting that a "complex public" be engaged. A complex public is one that is so large, less well-defined and heterogeneous that 
engagement is difficult for many reasons. Public involvement is often difficult even with small groups, which explains why so much of public engagement is really only token in nature.

Suggesting that every community member is equally capable of engaging in the process of data collection necessarily adds a level of complexity that will be unfamiliar to most transportation engineers and planners. We believe it is of critical importance to pursue such engagement however, as engaging the public in data collection can be part of the cultural education and transformation that is needed to increase rates of walking and biking. That is, the social learning of engaging in this public process may be an important component toward changing actual behavior.

\subsubsection{Programming Requirements}

Collecting GIS data in the field has historically required two pieces of software, one to program the tool and one to process the data. Both require expensive licensing: ArcPad and ArcPad Application Builder (cost: \$2,000) and ArcGIS (cost: \$15,000). On the other hand, ESRI, the developers of the ArcGIS software, have noted these trends as well, scheduling the release of integrated iPhone libraries with the subsequent release of its software. Nonetheless, the software distribution and business model used by ESRI has always targeted a more technical professional community.

The SPM model allows for more flexible pricing, and costs are based on the needs of the community. Programming smart phones is much more technical than the software assisted approach provided by ArcPad, but the software IDE (X-Code) is free and the distribution of the software can be universal (through the Apple App Store).

The SPM model requires significant programming expertise to develop the tool. All together, more time was spent writing code for the application than adjusting the survey instrument itself. Further, the survey was sometimes limited by the technical capacity of the software development team. The GISM model provides a much more structured, albeit limited, development environment. A digital survey is not inherently that different from a paper survey. Considering that public participation grew from grassroots mapping efforts in poor or underdeveloped communities, it is arguable how much technology adds to the quality of the data collection itself.

On the other hand, the survey is only one aspect of the data-collection process in that the logistics of distributing, collecting and digitizing survey data can present a significant hurdle. Thus, the SPM model did provide the ability to better handle data logistics.

\subsubsection{Base Data Requirements}

GIS-based data is either public domain and free or publicly accessible (i.e., through the Google Map data freely accessed with the Fix-This Tool). However, the SPM model used here did eliminate the need to pre-process map data since it relies on live display of online maps.

\subsubsection{Usability}

An important motivation in tool development via the iPhone platform was to create both a tool and a tool distribution system that did not require much technical knowledge or specialized 
hardware or software to use. From the user's point of view, the technical requirements are just an iPhone (or iTouch) and the ability to download an application from the Apple App Store. For average users, there is no real technical barrier to use. Our volunteers seemed remarkably comfortable using their finger to navigate maps and applications, much more so than previous PDA-based audit tools that required a stylus to enter data via ArcPad.

\subsubsection{Event Planning}

Public involvement requires a significant amount of planning, post-workshop data processing, map preparation and report generation. Workshops require a team of facilitators trained in active transportation issues, public facilitation, and participatory GIS tools to be present. A single, sixhour workshop requires at least three days of travel because there is pre-site analysis and postworkshop follow up that needs to be conducted.

Clearly, a model that does not rely on a community needing outside GIS experts or specialized GIS devices will be less expensive. And while there are certainly equity issues to consider in this new model when thinking about who does and does not have access to smart phones, the overall penetration of mobile phones, and the increasing penetration of smart phones into every day life for people across the economic and racial spectrum, makes the model of utilizing individually owned devices particularly appealing. For event planning then, participation does not need to be limited by the number of devices a facilitator brings to the effort, but can be more broadly accessible to a greater potential pool of participants. And if need be, individually owned smart phones can be supplemented with centrally distributed devices in order to include any underrepresented populations. Given that the devices need no expensive software or training, the number of devices, and therefore participants, involved in a built-environment audit are only limited by the desires of the organizing body, not by the expense of the software and associated devices.

\subsubsection{Simplicity}

Most people struggle to adopt new and unfamiliar technology. Involving people in data collection can create significant barriers. We have always noted that some individuals are quick to understand the mobile-mapping technology, while others never truly feel comfortable.

The same barrier is true with dealing with technical descriptors of the built environment. Some people feel comfortable adopting a new vocabulary to describe transportation issues, while others see the street environment in much more subjective terms. With the elimination of the workshop proceeding data collection, we wanted to make a tool that was as simple and selfevident as possible. Almost all volunteers felt comfortable describing the environment within the survey questions provided.

\subsubsection{Depth}

On the other hand, the built environment is a highly complex space. We have noted that through data collection, participants become aware of their street environment in much more nuanced and complete ways. Whereas opinion would previously be expressed in terms of very general fears, 
participants were much quicker to identify specific deficiencies in surrounding streets and intersections after having spent two to three hours of observation and note taking.

The scale of data collection should be appropriate to the particular objective at hand. Fine-scale data is important when assessing active-transport environments since local characteristics of the street environment can have profound impacts on how comfortable or safe an area is perceived to be. The open-ended structure of the SPM approach allows for the collection of a large amount of highly local data, but the open-ended input options may lead to data that is difficult to interpret in aggregate or at larger scales.

Somewhat general, subjective observations of the walking environment should not be confused with fine-grain and objective data collection. In fact, such subjective value maps of the environment may be more important as a first-cut way of focusing future data collection efforts to those streets and intersections of the city of greatest concern or importance. In this sense, objective data, which may be better conducted by persons with more training and/or experience, is still influenced and directed by public input.

\subsubsection{Data Management}

Any practitioner of GIS knows the value of data management. Data management becomes more complex as the sources of data become more varied. This is particularly true when a single source is made from the combined efforts of many persons. Not only is it hard to create a data structure whereby data integrity is maintained, it also becomes increasingly difficult for a GIS technician to check for accuracy and precision.

Automating the synchronization of data collection to a single source eliminates a principle source of human-caused data error. The distributed-participation framework allowed us to test a data-collection model by which data was automatically uploaded to a server. This task was made easier by creating an open-ended geographic system for saving data whereby each observation was logged to a specific X-Y coordinate.

By contrast, the GISM approach saves data directly to an underlying GIS data structure, which can make post-processing of the data much easier to analyze. However, the native GIS geodatabase does not natively handle complex database relationships. Thus, if two people comment on the same geographic feature, say a street segment, it is hard to resolve which should overwrite the other. Obviously, such exclusivity, or one-to-one relationships, becomes particularly limiting when dealing with subjective data, within which variance in data is expected.

Naturally, users are the most aware of issues along the corridors they travel. In an unstructured data-collection format carried out by a decentralized and unsupervised public, a type of datacollection paradox thus emerges: How does data get collected in areas with low active transportation use if predominantly active-transportation users are collecting the data? This is a challenge to take up once a wider scale adoption of a tool like the Fix-This Tool begins in earnest. 


\subsubsection{Interpretability}

Our initial work seems to indicate that even with a semi-homogenous group of assessors, there can be a wide variety of ideas about quality of an active-transportation environment. When multiple users commented on an area, a great range of qualitative valuation became apparent. In contrast to system-wide transportation planning at a regional scale, experiences at the micro scale - that experienced by pedestrians and cyclists who directly interact with their physical environment in an immediate way - is complex, with an almost unlimited number of real or perceived conditions that can influence decision making. Many built-environment research studies have tried (and failed) to isolate a minimal number of factors that actually matter for active-transportation users. We suggest that for the issue of livability there may need to be a rethinking of how to embrace the complexity and messiness of micro-environments, and to find ways to utilize data and experiences to improve conditions without unnecessarily homogenizing or summarizing complex environments.

We understand this may be difficult and require a fairly radical change in thinking. In a traditional data-driven decision paradigm, such inconsistency of evaluation across auditors would be a serious cause of concern as it would point to a lack of rigor in training and data collection. Our take on the variation, however, is that it illustrates that nature of plural knowledge. Aggregating or averaging data to have a singular result may mask the true variation of space and quality. We believe that there is a need for new ways of analysis that can take advantage of such "messy" data and, in fact, celebrate the fact that vibrant, livable spaces are often "messy" (that's what often makes them enjoyable). In addition, different responses to similar environments merely illustrate that there is a need to plan environments that accommodate a range of types of people. Thus, in some ways, developing new ways of using "messy" data also honors the very intent of community engagement by retaining an ability to treat input as the product of our heterogeneous society. 


\subsection{CONCLUSION}

The purpose of this project was to design a spatially based, data-collection tool that would allow community residents to collect data about their active-transportation environment in an easy way using technology they may already own. Drawing from past built-environment and GIS-audit tools, this work resulted in the creation of the Fix-This Tool, a simple-to-use, map-based tool on the iPhone to record the good and bad of local pedestrian and bicycle environments.

In testing the tool, we determined that no training was required for users to know what to do - a significant improvement from previous GIS-based audit tools that did require more extensive technological training. By basing the Fix-This Tool on the iPhone platform, users already had the basic technological skills to use the tool as the tool simply utilized standard means of navigating iPhone programs and functions.

This ease of use indicates tremendous potential to catalyze hundreds of thousands of Americans to document millions of instances of good and bad active-transportation situations in their communities. This is data that no top-down approach could ever collect, as aspects of the built environment of importance to pedestrians and cyclists are so micro-scaled that it is infeasible for government-based efforts to fully complete and keep updated. Moreover, temporary obstructions can be ongoing frustrations for active transportation, but in traditional transportation data gathering such temporary situations (i.e., a car parked across a sidewalk) would go uncollected or discounted as impractical to collect or to respond to. With the Fix-This tool, such subjective and temporary data, when collected by hundreds of residents in a given community, can add up to larger meaning with policy and programmatic implications.

With the potential of thousands of resident-collected data points in any given community, there will need to be new ways for agency officials and researchers to understand and utilize such data to make appropriate change. Combining the qualitative and subjective nature of some of this community-based data, with an inability to effectively regulate reliability or consistency across data collectors, may present challenges to professionals used to transportation data that is void of these characteristics. Yet, empowering community members to identify issues in their community, record spatial and attribute data about those issues, and communicate that data for public consumption and eventual action is extremely compelling on many levels. The smart phone era necessitates new ways of thinking about how to exploit the vast opportunity of community engagement, and how to translate their engagement and data collection into action.

There is tremendous potential for a new era of communication between communities and transportation planning and engineering professionals, whereby community members are empowered to collect community-relevant transportation data using smart phone technology they already own. The Fix-This Tool is one such avenue for doing that. 


\subsection{REFERENCES}

Arnstein, S.R. "Ladder of Citizen Participation." Journal of the American Institute of Planners 35, no. 4 (1969): 216-224.

Bull, R., J. Petts, and J. Evans. "Social learning from public engagement: dreaming the impossible?" Journal of Environmental Planning and Management 51, no. 5 (2008): 701 716.

Craig, W.J., T.M. Harris, and D. Weiner. Community participation and geographic information systems. Taylor \& Francis, 2002.

English, K., and L.S. Feaster. Community geography: GIS in action. Redlands, CA: Environmental Systems Research Institute, 2003.

Harris, T. "Empowerment, Marginalization and "Community-Integrated" GIS." Cartography and Geographic Information Systems 25, no. 2 (1998): 67-76.

Obermeyer, N.J. "The Evolution of Public Participation GIS." Cartography and Geographic Information Systems 25, no. 2 (1998): 65-66.

O'Looney, J. Beyond maps: GIS and decision making in local government. Redlands, CA: Environmental Systems Research Institute, Inc., 2000.

Schlossberg, M., and C. Brehm. "Participatory GIS and Active Transport: Collecting Data and Creating Change." Transportation Research Record: Journal of the Transportation Research Board 2105 (2009): 83-91.

Talen, E. "Bottom-Up GIS: A New Tool for Individual and Group Expression in Participatory Planning." Journal of the American Planning Association 66, no. 3 (2000): 279-294. 


\title{
APPENDIX A: PARTICIPANT INVITATION
}

\author{
IPHONE WALKING AND BIKING ASSESSMENT PROJECT
}

PARTICIPANT INVITATION

\section{[insert date] \\ Dear [insert name],}

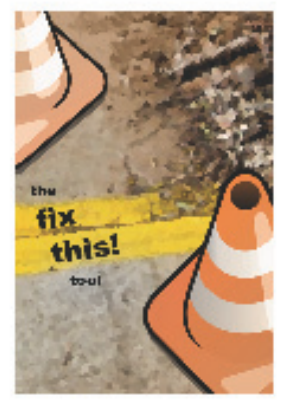

My name is Marc Schlossberg and I am a faculty member from the Department of Planning, Public Policy and Management at the University of Oregon working in collaboration with the UO InfoGraphics Lab. I am writing to invite you to participate in my research study mapping the walkability and bikability of streets to and from the UO campus using custom iPhone applications and devices.

You're eligible to be in this study because you are a member of the University of Oregon community or live/work in the local area. I obtained your contact information from [describe source].

If you decide to participate in this study, you will be issued an iPhone with a customized mapping application to document barriers to walking and biking on routes to and from the UO campus. This project is funded by the Oregon Transportation Research and Education Consortium.

Remember, this is completely voluntary. You can choose to be in the study or not. If you'd like to participate or have any questions about the study, please email our research team at citylink@uoregon.edu.

Thank you very much.

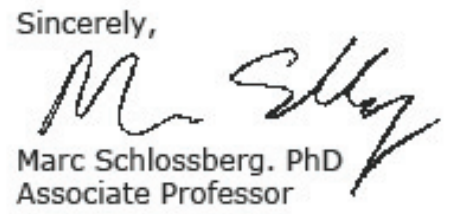

Department of Planning, Public Policy and Management, University of Oregon Co-Director, Sustainable Cities Initiative, University of Oregon Associate Director, Oregon Transportation Research \& Education Consortium (OTREC) 


\title{
APPENDIX B: PARTICIPANT CONSENT FORM
}

\author{
IPHONE WALKING AND BIKING ASSESSMENT PROJECT \\ PARTICIPATION CONSENT FORM
}

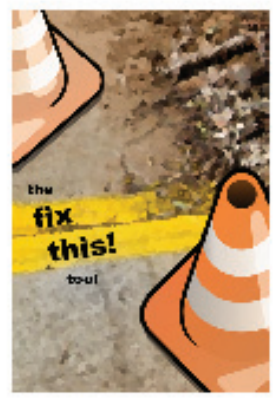

You are invited to participate in a research study conducted by Marc Schlossberg, PhD, a faculty member from the Department of Planning, Public Policy and Management at the University of Oregon.

We are using custom iPhone applications to map barriers to walking and biking along routes to and from the UO campus. You were selected as a possible participant in this study because you may have an interest in evaluating local streets and intersections in their capacity to support walking and biking.

If you decide to participate, please respond to this email and let us know that you would like to participate. You would be issued an iPhone loaded with our custom application to use for approximately two weeks, to record locations of your choice where there may be barriers to walking and biking. We ask that you collect this information during walking or biking trips and not from your car. This research is important to inform University and City of Eugene decision-makers about the areas that need focused attention to improve walking and biking. Apart from these benefits, I cannot guarantee that you personally will receive any benefits from this research.

Any information that is obtained in connection with this study and that can be identified with you will remain confidential and will be disclosed only with your permission. Subject identities will be kept confidential. We will not store personally identifiable information with the data that you collect. However, the data that you collect will be used to prepare maps and reports to improve walking and biking in the community.

Your participation is voluntary. Your decision whether or not to participate will not affect your relationship with the University of Oregon or your department. If you decide to participate, you are free to withdraw your consent and discontinue participation at any time without penalty. Funding for this project comes from the Oregon Transportation Research and Education Consortium (OTREC).

If you have any questions for the project team, please feel free to contact Graduate Research Fellows Cody Evers at cevers@uoregonedu or Christo Brehm at cbrehm@uoregon.edu. Professor Marc Schlossberg can be reached at schlossb@uoregon_edu or through the Department of Planning, Public Policy and Management - 119 Hendricks Hall, 1209 University of Oregon, Eugene, OR 97403.

If you have questions regarding your rights as a research subject, contact the Office for Protection of Human Subjects, University of Oregon, Eugene, OR 97403, (541) 346-2510. This Office oversees the review of the research to protect your rights and is not involved with this study.

Your signature indicates that you have read and understand the information provided above, that you willingly agree to participate, that you may withdraw your consent at any time and discontinue 


\section{APPENDIX C: POST-ASSESSMENT SURVEY}

\section{POST-ASSESSMENT PARTICIPANT SURVEY}

NAME

DATE

Please spend 5 minutes answering the following questions below. This information is just as important as the audit information you just collected. Your responses are greatly appreciated.
$\square$ Male
$\square$ Female
1. Your gender?
2. How old are you?
3. Are you a student?
$\square<18$
ㄷ 19-24
$\square$ Yes
25-35
$35-50$
$\square>50$

4. Hours / week that you walk: You walk to:

5. Hours / week that you bike:

$\square$ Recreate

You bike to:

$\square$ Shop

$\square$ Commute to work or school

$\square$ Recreate

$\square$ Other:
$\square$ Shop
C Commute to work or school
$\square$ Other:

6. How many hours do you drive per week:

Consider the following written statements. With each statement, circle the response that best describes the degree to which you agree or disagree.

7. I am very aware of my safety and comfort while I am biking or walking

8. I believe that my perceptions of safety and comfort are similar to those of other persons

9. I felt that I was able to effectively describe my walking and biking concerns using the mapApp $\square$ Strongly Agree

$\square$ Agree

$\square$ Disagree

$\square$ Strongly Disagree

$\square$ Strongly Agree

$\square$ Agree

$\square$ Disagree

$\square$ Strongly Disagree

$\square$ Strongly Agree

$\square$ Agree

$\square$ Disagree

Strongly Disagree

IPHONE WALKING AND BIKING ASSESSMENT PROJECT 



\section{SOTREC \\ AND EDUCATION CONSORTIUM}

P.O. Box 751

Portland, OR 97207

OTREC is dedicated to stimulating and conducting collaborative multi-disciplinary research on multi-modal surface transportation issues, educating a diverse array of current practitioners and future leaders in the transportation field, and encouraging implementation of relevant research results. 